\title{
Microstrip Feed Trapezoidal Shape Antenna Array with Defected Ground Structure for S Band Applications
}

\author{
Suganthi Santhanam, Thiruvalar Selvan Palavesam
}

\begin{abstract}
In this proposal new trapezoidal patch microstrip feed antenna array with ground defected by square shape is designed for detailed antenna parameter study in terms of return loss, VSWR, gain and radiation pattern for $S$ band applications from 2 to $3 \mathrm{GHz}$. The bandwidth and radiation properties of four radiating element arranged in $2 \times 2$ array has been improved by defecting half of the ground by etching square shape opposite to the vertical feed point. $30 \times 70 \times 1.6 \mathrm{~mm}$ dimension structure has been fabricated in FR4 substrate for low cost applications and performance analyzed in three different planes. With comparison of four element array with full ground, the proposed array with defected ground has proved the improvement in behavior with return loss of $-34.687 \mathrm{~dB}$ and ideally fit with VSWR of 1.038. Parametric study with feed length and substrate thickness has also been performed optimized decision of structure dimension. This study reveals that by reducing the substrate thickness and increasing the feed length, we can improve the performance of loss reduction. The front view has been simulated with full ground and defected ground for comparison and the compared results shows that the loss reduction of $-22 \mathrm{~dB}$ has been achieved with VSWR value of 1.03 from 2.28 for defected ground structure. The designed structure has been simulated with CST software and the comparison of simulated results has conform that the proposed structure can be used for $S$ band application like airport surveillance radars with wide bandwidth of $120 \mathrm{MHz}$ and gain of $3.52 \mathrm{dBi}$. Comparison has been made between the proposed antenna array and the antennas available in literature with respect to bandwidth gain, reflection coefficient and defection type for better understanding.
\end{abstract}

Keywords: Antenna Array, Microstrip Feed, Radiation Pattern, Return Loss, S Band Applications, Trapezoidal Patch.

\section{INTRODUCTION}

\section{P} resent wireless communication system has increased market demand and its rapid development leads to much effort in antenna invention with specific significance. Different antenna in separate can now a day's used o replace

Manuscript received on April 19, 2021.

Revised Manuscript received on June 16, 2021.

Manuscript published on June 30, 2021.

* Correspondence Author

Suganthi Santhanam*, Professor, K. Ramakrishnan College of Technology, Tiruchirappalli (Tamil Nadu), India. Email: tvssugi@gmail.com, suganthis.ece@krct.ac.in

Thiruvalar Selvan Palavesam, Professor, Department of Electronics and Communication Engineering, SRM TRP Engineering College, Tiruchirappalli (Tamil Nadu), India. Email: thiruvalar@gmaill.com

(C) The Authors. Published by Blue Eyes Intelligence Engineering and Sciences Publication (BEIESP). This is an open access article under the CC BY-NC-ND license (http://creativecommons.org/licenses/by-nc-nd/4.0/) single antenna which cannot operate at all frequencies. Development of MIC [1] with multifunction wireless systems

has drawn high attention in low cost, wideband [2] and small size antenna research.

Microstrip antennas are most suitable in wireless application in medical, sensor and agriculture fields due to its light weight [3], easy fabrication and low profile, excitation surface wave [4], narrow bandwidth and low gain are the notable limitations in microstrip antennas [5]. The operating bandwidth of microstrip patch antenna can be enhanced by increasing the substrate thickness [6], external matching, proximity coupling [7], coplanar waveguide [8], and separation of feed and antenna, defected ground structure and by parasitic tuning element. Defected ground structure is preferred in wireless applications for reducing the size [2] and improving the performance. Low profile, multiband and wider bandwidth antennas are in extensive interest for wireless, business, medical and military applications.

In present cellular communication planar antenna is mostly preferred due to its low cost [9], easy integration, small size [10] and simple easy integration [11]. To overcome the small gain, narrow bandwidth and high dielectric loss limitation, array topologies are introduced by many researches for better efficiency with low dimension structure [12]. Out of several planar topologies, patch antenna is preferred for its easy design and low cost [13]. Based on the discussion sofar, in this paper, we have proposed the design of defected ground structure based microstrip trapezoid patch antenna for low frequency $\mathrm{S}$ band applications.

DGS was proposed at first by Park et.al with photonic band gap (PBG) structure for low pass planar circuits [14]. In DGS, specific pattern etching is done in ground plane to disturb the current distribution which in turn changes the transmission line characteristics to obtain proper band stop property [15]. Addition of DGS increase the inductance and gap capacitance which in turn change the surface current that affects the phase velocity of the current [16]. The defection in ground plane of DGS can be made by slot for [17] higher gain applications. Different configuration of DGS has been proposed in literature for various applications like for DGS with three U shaped element [A], high gain [18], [19], dual band operation [18], triple band [19] application, size reduction of antenna [19] [1], bandwidth enhancement [21], dual polarization [22], circular polarization [23], C band applications [24], S band application [25], X band application [26], wireless multiband [27] applications and for MIMO (Multiple Input Multiple Output) [28] applications.

\section{Published By:}

Blue Eyes Intelligence Engineering and Sciences Publication

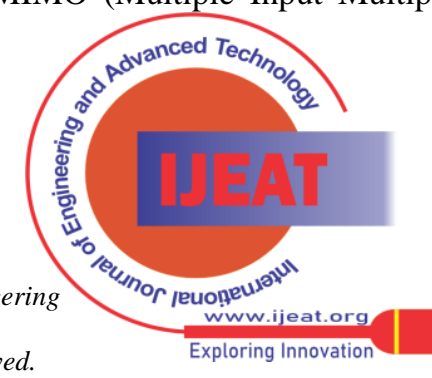


In this paper, we have proposed the defected ground microstrip trapezoid patch antenna for higher bandwidth and low loss S band applications. The proposal reported involves the etching of ground plane in rectangular slot at backside with array of four trapezoidal radiating patch in $2 \times 2$ form in front side. After many trail investigation, the front 2 x 2 array element has been loaded with square slot etching in ground plane to get reduction in return loss. The partial half ground has been further etched in ground has been further etched in square slot with micrstrip feed and is fabricated in FR4 substrate. The loss characteristics has been enhanced by modifying the initial full ground to half in size with respect to vertical direction of feed and then subtracting the half ground by square slot. The simulated results match with ideal property of microstrip antenna. The presentation of the paper is structured as follows: Antenna design and configuration is presented in second section. The third section presents the parametric study for matching and loss analysis followed by simulation results and discussion in fourth section. Finally the last section concludes our work with suggestion for extension in future.

\section{ANTENNA DESIGN AND CONFIGURATION}

This paper describes the trapezoidal shape four element (2 $x 2$ ) antenna arrays with defected ground plane and operating frequency range from $2.93 \mathrm{GHz}$ to $2.81 \mathrm{GHz}$ with $2.872 \mathrm{GHz}$ resonant frequency. The antenna is designed on FR4 substrate having thickness of $1.6 \mathrm{~mm}$, loss tangent 0.025 and dielectric permittivity of 4.3. Copper conductor having thickness of $0.035 \mathrm{~mm}$ is considered for simulating the microstrip line, ground and radiating element. The front and back view of proposed array antenna is shown in figure .1. The optimized dimensions were calculated with the help of formula in literature and the finalized dimension of front and back view is given in Table.1.

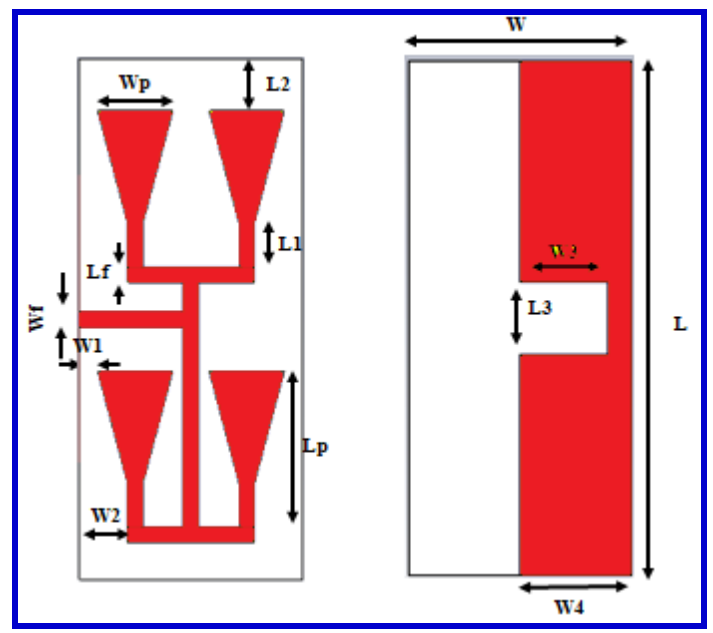

Fig.1 . Front and back view of proposed trapezoidal patch microstrip antenna array with defected ground structure

In the first step, the single trapezoid antenna is designed and simulated and optimized using Finite Integration Technique (FIT) based CST simulation software. Many times trial made to optimize the dimension for better antenna parameters results. Though we received better performance with single element, we structured 2 x 2 radiating patch array

to change the impedance property using mutual impedance between individual radiating elements.

Table -1: Dimension in $\mathrm{mm}$ for the proposed antenna array

\begin{tabular}{|c|c|c|c|}
\hline $\begin{array}{c}\text { Paramet } \\
\text { er }\end{array}$ & Value & Parameter & Value \\
\hline $\mathrm{W}$ & 30 & $\mathrm{~L}$ & 70 \\
\hline $\mathrm{Wf}$ & 2 & $\mathrm{Lf}$ & 20 \\
\hline $\mathrm{Wp}$ & 10 & $\mathrm{Lp}$ & 21 \\
\hline $\mathrm{W} 1$ & 2.5 & $\mathrm{~L} 1$ & 6 \\
\hline $\mathrm{W} 2$ & 6.5 & $\mathrm{~L} 2$ & 7 \\
\hline $\mathrm{G}$ & 0.5 & $\mathrm{Gl}$ & 14.5 \\
\hline
\end{tabular}

In the second step we designed 2 x 2 array within the single element front dimension of $30 \times 70 \times 1.6 \mathrm{~mm}$ to impose size reduction. In the first step, the single trapezoid antenna is designed and simulated and optimized using Finite Integration Technique (FIT) based CST simulation software. Many times trial made to optimize the dimension for better antenna parameters results. Though we received better performance with single element, we structured 2 x 2 radiating patch array to change the impedance property using mutual impedance between individual radiating elements. In the second step we designed $2 \times 2$ array within the single element front dimension of $30 \times 70 \times 1.6 \mathrm{~mm}$ to impose size reduction. The final achieved front side of proposal consists of 2 x 2 antenna array on single of $0.035 \mathrm{~mm}$ foil on one side and FR4 substrate on other side. Based on transmission line model, the width of trapezoid patch is decided first and then length is calculated by considering the fringing field. We simulate this array with full ground and the device resonates at $1.891 \mathrm{GHz}$ with $-26.18 \mathrm{~dB}$ return loss and impedance bandwidth of $85.5 \mathrm{MHz}(1.85 \mathrm{GHz}-1.93 \mathrm{GHz})$. To improve the loss behavior and to shift the resonant frequency in $\mathrm{S}$ band range, we introduced the defection in ground by etching the ground in square slot at center and opposite to feed point. Due to this defection, the array antenna operates at $2.872 \mathrm{GHz}$ resonant with $-34.691 \mathrm{~dB}$ reflection coefficient.

\section{PARAMETRIC STUDY}

The parametric investigation is done for trapezoid patch antenna array for optimizing the dimension.

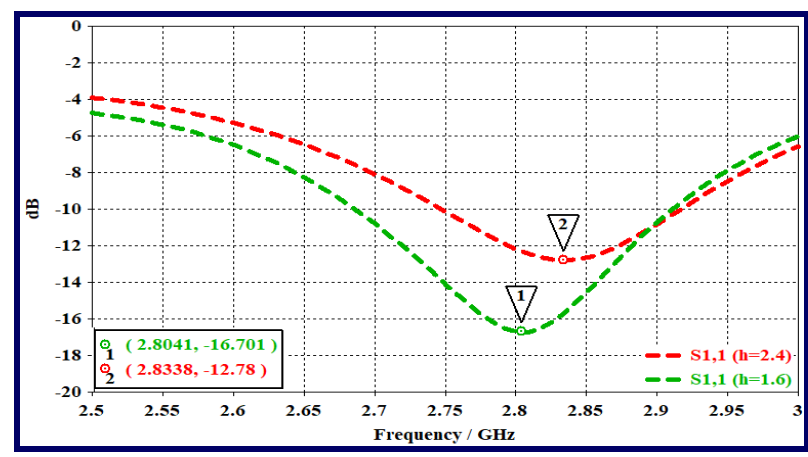

(a)

Published By:

Blue Eyes Intelligence Engineering and Sciences Publication 


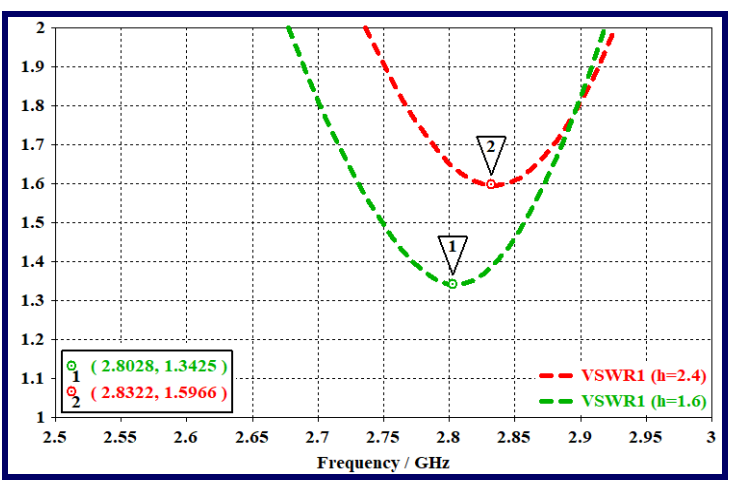

(b)

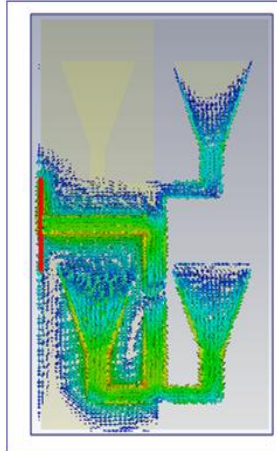

(c)

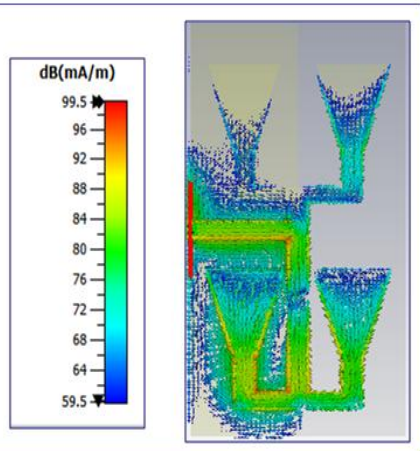

(d)
Fig.2. Parametric study plots for proposed antenna array (a) Return loss (b) VSWR (c) Current distribution for substrate thickens of $1.6 \mathbf{~ m m}$ (d) Current distribution for substrate thickens of $2.4 \mathrm{~mm}$

The parameters taken for study are substrate thickness and feed length. The FR4 substrate thickness of $1.6 \mathrm{~mm}$ and $2.4 \mathrm{~mm}$ which are mostly used for fabrication has been taken at first for study.

Figure 2 shows the reflection coefficient and VSWR for the two thickness values. This figure shown that when the thickness increased, the return loss reduced with wider bandwidth. The bandwidth improvement of $0.7 \mathrm{GHz}$ is achieved with $-3.9 \mathrm{~dB}$ return loss reduction as shown in figure 2 (a) for thickness of $1.6 \mathrm{~mm}$. Similarly the arena ideal behavior in terms of VSWR has been shown in figure 2 (b) has been improved from 1.5 to 1.34 which falls in ideal range of 1 to 1.5. The current distribution is also better and the maximum current is improved from $99.47 \mathrm{~mA} / \mathrm{m}$ to 101.25 $\mathrm{mA} / \mathrm{m}$ as shown in figure. 2 (d).

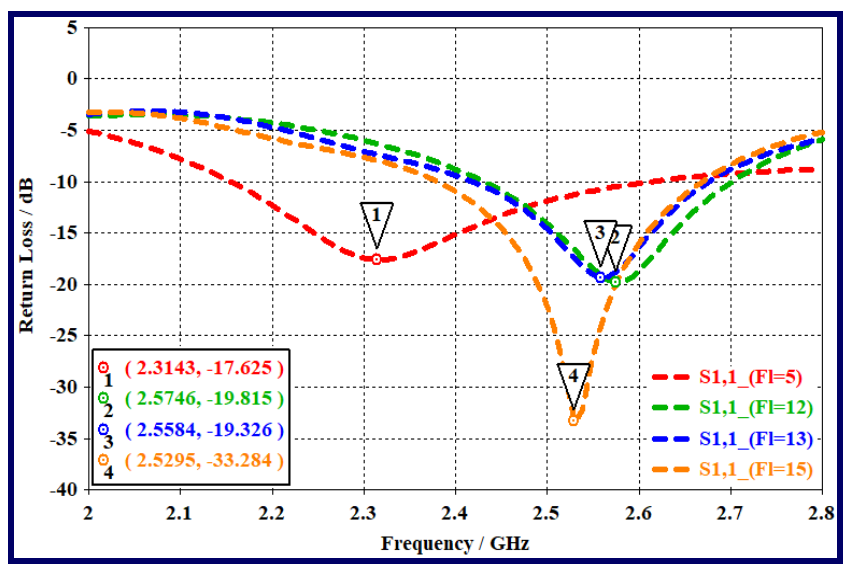

(a)

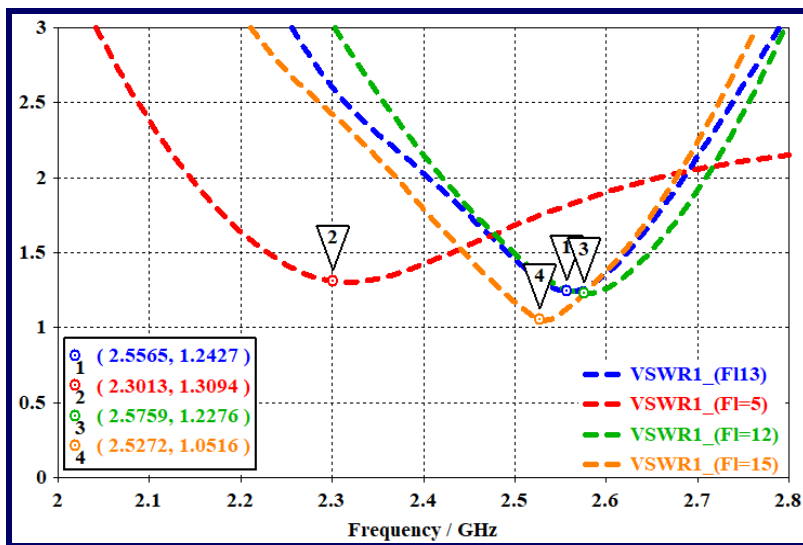

(b)

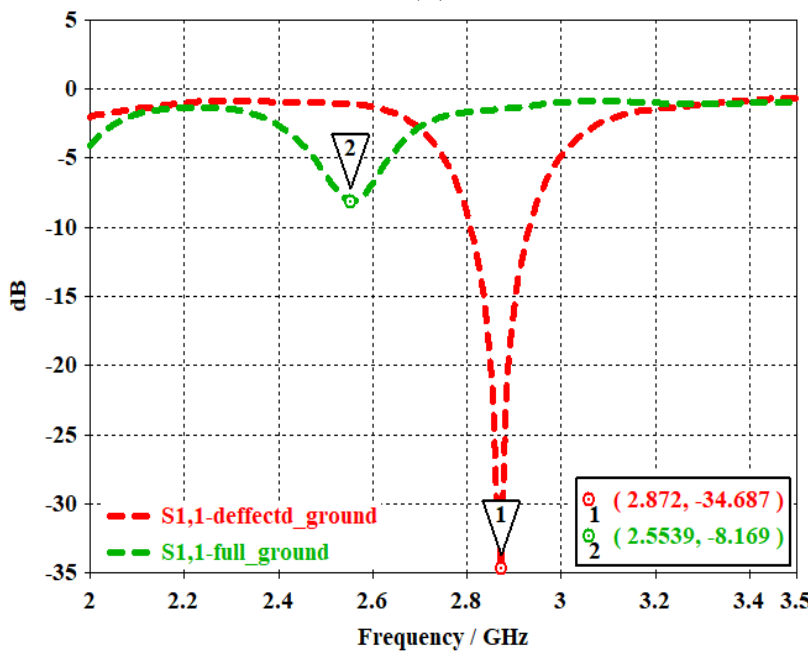

(c)

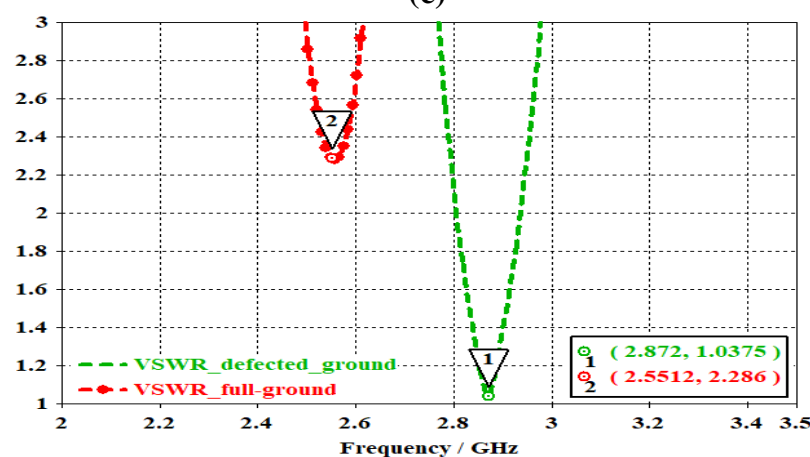

(d)

Fig.3. Parametric study plots for proposed antenna array

(a) Return loss (b) VSWR (c) Reflection coefficient comparison with and without defected ground (d) VSWR comparison with and without defected ground

The next parameter for study is the length of feed. As shown in figure 3 , we have analyzed the return loss, VSWR, electric and magnetic field distribution and current distribution for different values of feed length from $5 \mathrm{~mm}$ to $15 \mathrm{~mm}$. Figure 3 (a) shows that the increase in feed length reduces the return loss and the array is closure to ideal behavior in terms of VSWR as shown in figure 3 (b) and the impedance bandwidth has also been raised to maximum value

\section{Published By:}

Blue Eyes Intelligence Engineering

and Sciences Publication

(C) Copyright: All rights reserved.

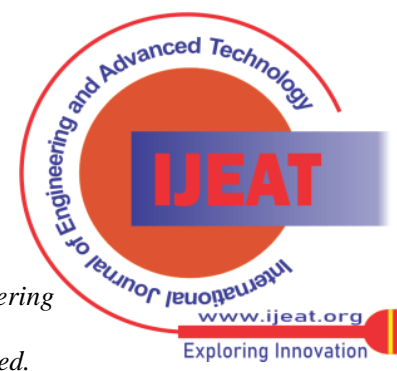


of $0.17 \mathrm{GHz}$. Hence in our design, we have chosen $1.6 \mathrm{~mm}$ as substrate thickness for our further analysis. In figure 3 (c) and (d) the effect of ground has been compared for reflection coefficient and VSWR. The front view is simulated with entire ground in back and defected ground with Single Square opposite to the vertical center feed point and the results are compared as in figure .3. It is observed that the reflection coefficient allowable range of $<-10 \mathrm{~dB}$ has been attained only with defected ground and the return loss has been highly reduced from $-8.11 \mathrm{~dB}$ to $-34.69 \mathrm{~dB}$. The recommendation of defected ground for the proposed front view of trapezoid patch has been ensured in VSWR comparison having 1.04 with DGS as compared to 2.29 with full ground.

\section{SIMULATED ANTENNA PARAMETERS AND DISCUSSION}

We have simulated the defected ground $2 \times 2$ trapezoid microstrip fed antenna array with CST simulation software and the results are review here one by one. The feed point called port transmission property has been analyzed in terms of incident (i1) and reflected wave $(01,1)$ amplitude versus time. The reflected wave amplitude is delayed and distorted and the transmission of $0.6 \mathrm{~W}(0.93 \mathrm{~W}-0.33 \mathrm{~W})$ has been proved as shown in figure 4 (a). Figure 4 (b) represents the reflection coefficient of the proposed antenna array which resonates at $2.872 \mathrm{GHz}$ with return loss of $-34.691 \mathrm{~dB}$ and the bandwidth edges at $2.81 \mathrm{GHz}$ and $2.93 \mathrm{GHz}$ leads to impedance bandwidth of $122.8 \mathrm{MHz}$.

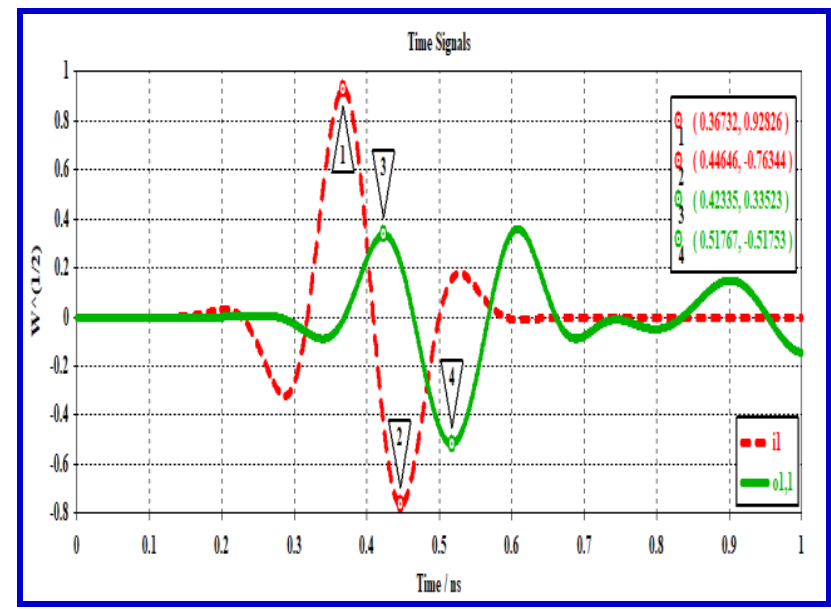

(a)

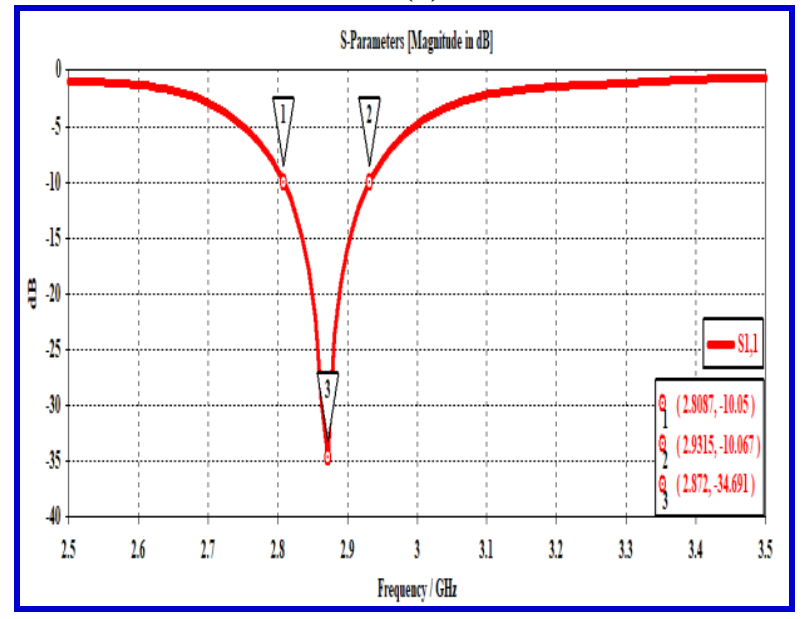

(b)

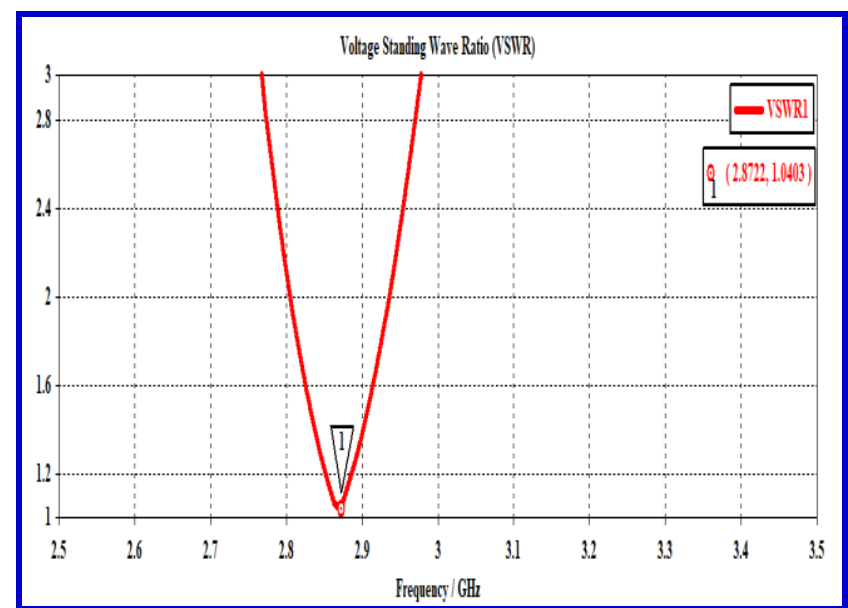

(c)

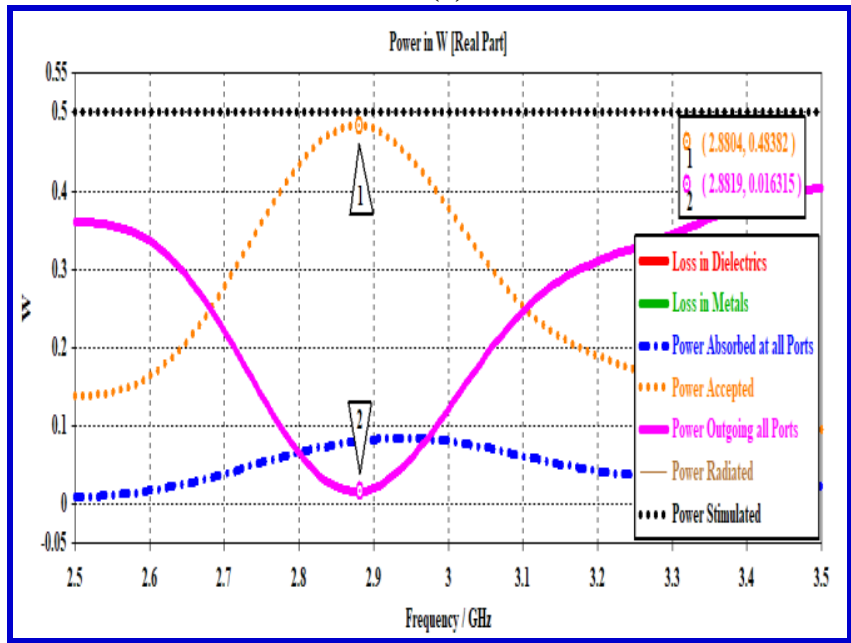

(d)

Fig..4 Simulation properties of proposed antenna array (a) Port signals (b) return loss (c) VSWR (d) losses in different layers of structure

The voltage standing wave ratio (VSWR) which is an element of reflection coefficient calculated for the proposal is 1.04 at resonant frequency $2.872 \mathrm{GHz}$ as shown in figure 4(c). The range of power simulated, absorbed and accepted at all ports of proposed array is shown in figure 4(d). It is observed that the power simulated is very closure to power accepted at resonant frequency and the power absorbed at all ports is also less than 0.1 watt in the simulated frequency range from $2.5 \mathrm{GHz}$ to $3.5 \mathrm{GHz}$ in $\mathrm{S}$ band.

Figure 5 shows the far field pattern of proposed antenna array in terms of its E field, $\mathrm{H}$ field, gain and power pattern. The simulated antenna patterns are compared with different plane at theta $=90^{\circ}$, Phi $=0^{\circ}$ for XZ plane and $\mathrm{Phi}=90^{\circ}$ for YZ plane as shown in figure 5, 6 and 7. As shown in figure 5 (a), 6(a) and \& 7(a), the horizontal plane (H field) has maximum amplitude of $-42.7 \mathrm{~dB}(\mathrm{~A} / \mathrm{m})$ in XZ plane compared to $\mathrm{YZ}$ plane with angular width of $220.1^{\circ}$. The main lobe direction $\left(115^{\circ}\right)$ is also high in this $\mathrm{XZ}$ plane as compared to $45^{\circ}$ in $\mathrm{YZ}$ plane. This simulated result has revealed that the proposed antenna is best suited for magnetic field radiation in $\mathrm{XZ}$ plane.

Published By:

Blue Eyes Intelligence Engineering and Sciences Publication

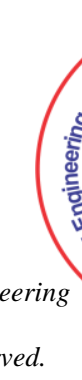




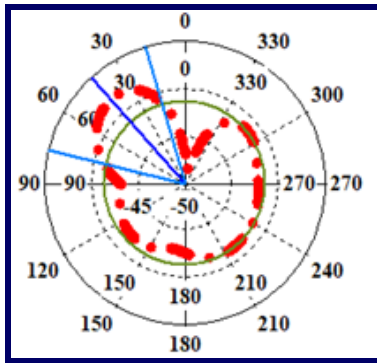

(a)

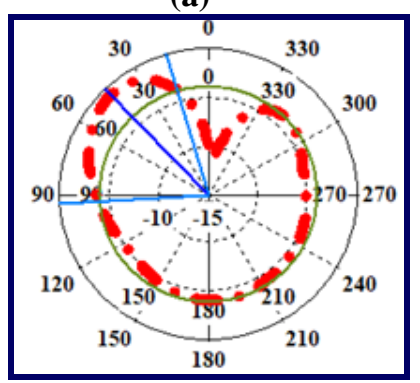

(c)

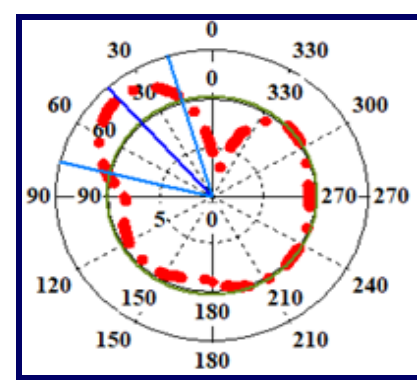

(b)

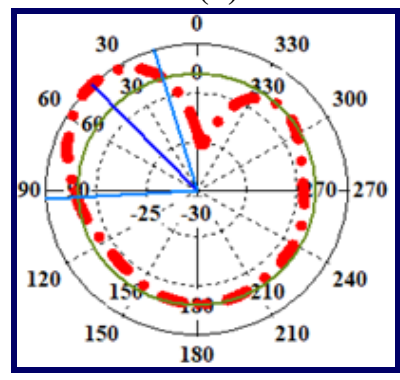

(d)
Fig. 5.Farfield radiation pattern of proposed antenna array with Theta $=90^{\circ}$ ( a) $\mathrm{H}$ field (b) E field (c) Gain (d) Power pattern

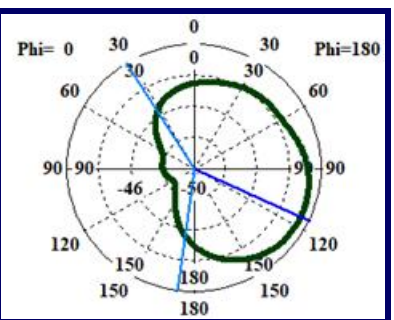

(a)

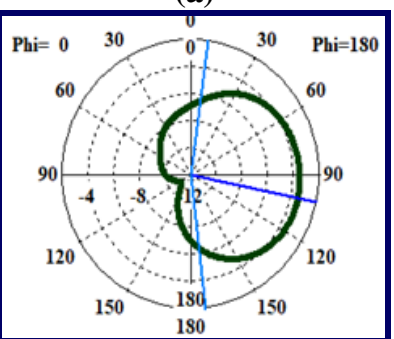

(c)

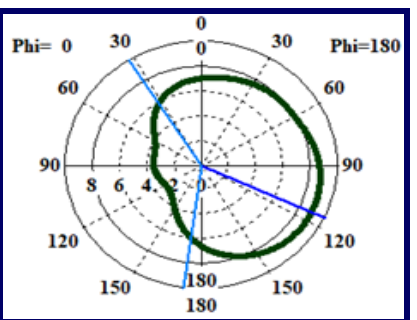

(b)

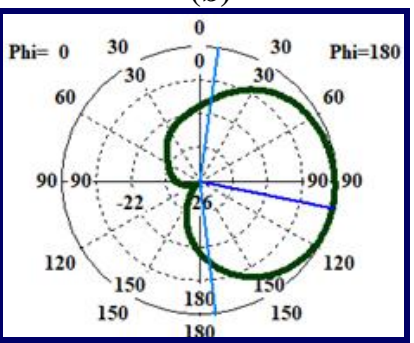

(d)
Fig. 6.Farfield radiation pattern of proposed antenna array with $\mathrm{Phi}=0^{\circ}$ (XZ plane) (a) $\mathrm{H}$ field (b) E field (c) Gain (d) Power pattern

The $\mathrm{E}$ field or the vertical plane has the maximum amplitude of $-13.4 \mathrm{~dB}(\mathrm{~V} / \mathrm{m})$ in theta $=0^{\circ}$ with angular width of $60.2^{\circ}$ which is three times higher in both $\mathrm{XZ}$ and $\mathrm{YZ}$ plane with $220.1^{\circ}$. The angular width is defined as the angular restriction below which the power does not fall under half of its maximum value. Hence the proposed antenna array is efficient in vertical plane radiation with maximum main lobe magnitude of $12.5 \mathrm{~dB}(\mathrm{~V} / \mathrm{m})$ as shown in figure 7 (b) for YZ direction compared to $\mathrm{ZX}$ plane as in figure 6 (b). Figure 5 (c), 6 (c) and \& 7 (c) shows the simulated gain in positive $x$ direction, $\mathrm{XZ}$ plane and $\mathrm{YZ}$ plane. The simulated gain is $0.885 \mathrm{dBi}$ in parallel $\mathrm{Z}$ axis, $3.52 \mathrm{dBi}$ in $\mathrm{XZ}$ plane and 1.25 $\mathrm{dBi}$ in $\mathrm{YZ}$ plane. When compared to other planes, the $\mathrm{XZ}$ plane gain exhibits higher gain of $3.52 \mathrm{dBi}$ with lower side lobe of -0.7 which is less than $-10 \mathrm{~dB}$. Hence the proposed array structure is highly suitable for high gain field applications.

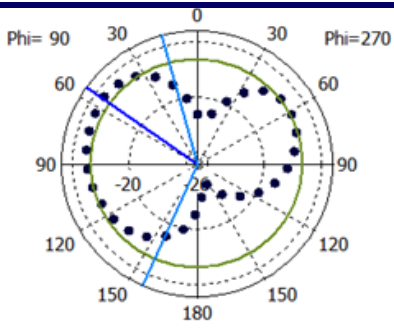

(a)

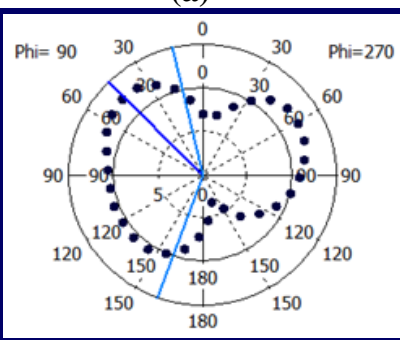

(c)

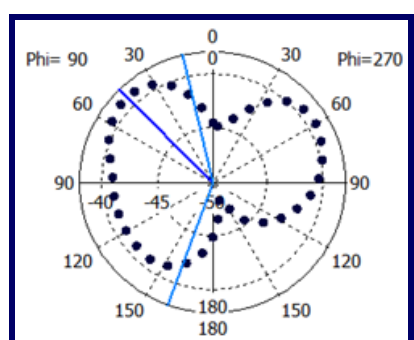

(b)

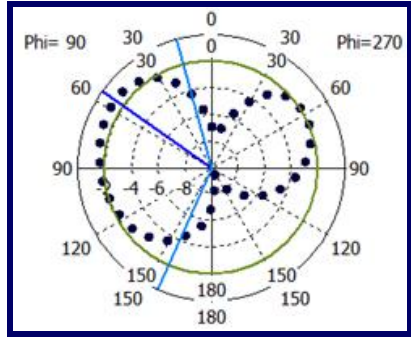

(d)
Fig.7.Farfield radiation pattern of proposed antenna array with $\mathrm{Phi}=90^{\circ}$ (YZ plane) (a) H field (b) E field (c) Gain (d) Power pattern

The power pattern as the square of the electric and magnetic fields magnitude in different planes has been plotted in figure 5 (d), 6 (d) and 7(d) respectively for positive $\mathrm{X}$ direction, $\mathrm{XZ}$ plane and $\mathrm{YZ}$ plane. From these comparison, the power pattern in $\mathrm{YZ}$ plane has the maximum magnitude of $15.9 \mathrm{~dB}\left(\mathrm{~W} / \mathrm{m}^{2}\right)$ in angular width of $140.7^{\circ}$ with lower side lode of $0.7 \mathrm{~dB}$. The comparison of the proposed array antenna for S band applications with existing antennas is shown in Table 2 with its essential parameters. It proved that the proposed array antenna is fit with all its ideal properties and the cost of the proposed antenna is low as it is fabricated on FR4 substrate.

Table - 2: Comparison of proposed array antenna with existing structures in literature

\begin{tabular}{|c|c|c|c|c|c|}
\hline Reference & $\begin{array}{l}\text { Dimension } \\
(\mathbf{m m})\end{array}$ & $\begin{array}{c}\text { Decoupling } \\
\text { Techniques }\end{array}$ & $\begin{array}{c}\text { Reflection } \\
\text { coefficient } \\
\text { (dB) }\end{array}$ & $\begin{array}{l}\text { Bandwidth } \\
\mathbf{( M H z )}\end{array}$ & $\begin{array}{c}\text { Gain } \\
\mathbf{( d B i})\end{array}$ \\
\hline $\mathrm{A}$ & $30 \times 30$ & U slot & 10 & Not given & $\begin{array}{c}\text { Not } \\
\text { given }\end{array}$ \\
\hline 9 & $50 \times 50$ & $\begin{array}{c}\text { E,C \& H } \\
\text { slots }\end{array}$ & 24 & 49.6 & 6.31 \\
\hline 2013 & $24 \times 20$ & slot & 10 & 300 & $\begin{array}{c}\text { Not } \\
\text { given }\end{array}$ \\
\hline 2014 & $22 \times 20$ & $\begin{array}{c}\text { Different } \\
\text { English } \\
\text { letters }\end{array}$ & 25 & Not given & 2.14 \\
\hline $2014-1$ & $30 \times 30$ & Half ground & 46 & 120 & 3 \\
\hline 2016 & $22.8 \times 18.6$ & Slot etching & 17 & 100 & 1.93 \\
\hline 2018 & Not given & $\begin{array}{c}\text { Slot with T } \\
\text { junction }\end{array}$ & 14 & 100 & 10.9 \\
\hline $2020-2$ & $32 \times 32$ & Square slot & 28 & 540 & 4.47 \\
\hline This paper & $30 \times 70$ & Square slot & 35 & 120 & 3.52 \\
\hline
\end{tabular}

\section{CONCLUSION}

A simple design microstrip vertical single feed trapezoidal patch 2 x 2 array antenna with square shape defected ground has been proposed for $\mathrm{S}$ band applications.

Published By:

Blue Eyes Intelligence Engineering and Sciences Publication 
The reflection co efficient and impedance bandwidth has been improved by arranging four element in array. Good radiation pattern with peak gain

of $3.52 \mathrm{dBi}$ in acceptable 3

$\mathrm{dB}$ bandwidth has been achieved in low cost FR4 substrate structure. The resonance frequency shift from $1.891 \mathrm{GHz}$ to $2.872 \mathrm{GHz}$ is achieved with compact structure by replacing single patch by four radiating element in same size. To validate the proposed work, the parametric study in terms of substrate thickness feed length to compare the return loss, VSWR and current distribution has also been carried out. This proposed design and study could be useful in microstrip patch antenna array radiation characteristics analysis at different planes for Airport surveillance radars and for other $\mathrm{S}$ band application in the range of 2 to $3 \mathrm{GHz}$. This work can be extended with more configurations for grounding effect study with fabrication of best structure for validation.

\section{REFERENCES}

1. Hanae Elftouh, A. Naima, Touhami, Mohamed Aghoutane, Safae El

2. Amrani, Antonio Tazon and Mohamed Boussouis, "Miniaturized Microstrip Patch Antenna with Defected Ground Structure," Progress In Electromagnetics Research C, vol. 55, pp. 25-32, 2014.

3. C.A. Balanis, Antenna Theory: Analysis and Design 3rd edition, John Wiley \& Sons, Hoboken, NJ, 2005.

4. Ouadiaa Barrou, Abdelkebir El Amri, Abdelati Reha, "Microstrip Patch Antenna Array and its Applications: a Survey," IOSR Journal of Electrical and Electronics Engineering, vol 15, no. 1, pp. 26-38, 2020.

5. C. A. Balanis, "Antenna theory, analysis and design", John Wiley and Sons. Inc., New York, 1982.

6. D. M. Pozar, "Microstrip antennas", IEEE Proc. Antenna Propagation, vol. 80, pp. 79-81, 1992.

7. C.S.Kim, J. I. Park, A. Dal, "A novel 1-D periodic defected ground structure for planer circuits", IEEE Microwave Guided Wave Letter, vol. 10, no. 4, pp. 131-133, 2000.

8. K. Shrivastav, Promad Kumar, Jugal Kishor, Rashid Mahmood, "Impedance BW enhancement technique in microstrip circuits by using DGS and DMS," Int. Symposium on Microwave and Optical Tech. New Delhi, pp. 532-535, 2009.

9. M. K. Khandelwal, M. K. Kanaujia and B. K Kumar, "Defected ground structure: fundamentals, analysis, and applications in modern wireless trends," International Journal of Antennas and Propagation, vol. 2017, pp.1-22, 2017. doi: 10.1155/2017/2018527.

10. Madan Mohan, Sudipta Das, Shambhu Mahato, Ashwani Kumar Chaudhary, "Size Reduction and Bandwidth Enhancement of Microstrip Patch Antenna by Proper Positioning of Patch above the Defected Ground Plane," International journal of innovative research in electrical, electronics, instrumentation and control engineering, vol. 1, no. 6, pp.265-271, 2013.

11. T.W.Chiou and K.L.Wong, "Design of Compact microstrip antennas with a slotted ground plane," IEEE APS International Symposium Digest, pp.732-735, 2011.

Elfergani, A.S. Hussaini, A.M.Abdalla, J. Rodriguez and R. Abd-Alhameed, "Millimeter Wave Antenna Design for 5G Applications," Optical and Wireless Convergence for 5G Networks, pp. 139-56, 2019.

12. M.A.Matin, "Review on millimeter wave antennas-potential candidate for $5 \mathrm{G}$ enabled applications," Advanced Electromagnetics, vol.5, pp.98-105, 2016.

13. Y. Liu, L.M. Si, M.Wei, P.Yan, P. Yang, H. Lu, C. Zheng,Y. Yuan, J.Mou and X. Lv "Some recent developments of microstrip antenna," International Journal of Antennas and Propagation, vol.2012, pp.1-10, 2012.

14. Chul-soo Kim, Jun-seok Park, Dal Ahn and Jae-bong Lim, "A novel 1-D periodic defected ground structure for planer circuits", IEEE Microwave Guided Wave Letter, vol. 10, no. 4, pp. 131-133, 2000.

15. M. Mabaso, and P. Kumar, "A dual band patch antenna for bluetooth and wireless local area networks applications," International Journal of Microwave and Optical Technology, vol. 13, pp.393-400, 2018.

16. S. L. Mallikarjun, P. M. Hadalgi and P. V. Hunagund, "Study on Effect of Rectangular DMS and DGS on 4 and 8 Elements Rectangular Microstrip Linear Array Antenna," Journal of
Microwaves, Optoelectronics and Electromagnetic Applications, vol. 10, no. 1, pp.13-23, June 2011.

17. K.O. Mabusha and P. Kumar, "A rectangular microstrip patch antenna for dual band wireless applications," Recent Advances in Electrical and Electronic Engineering, vol.13, pp.212-218, doi: 10.2174/ 2352096512666190215150917.

18. M.Mabaso and P.Kumar, "A microstrip patch antenna with defected ground structure for triple band wireless communications," Journal of Communications, vol. 14, pp.684-688, 2019, doi: 10.12720/jcm.14.8.684-688.

19. A.R. O.Mumin, R.Alias, J.Abdullah, J.Ali, S.H. Dahlan, R.A. Abdulhasan, A. Joret and H.M.Q.Rasheda, "Enhanced bandwidth and radiation specifications of patch antenna for WiMAX application, "IEEE Symposium on Computer Applications \& Industrial Electronics (ISCAIE), 2018.

20. C.K.Ghosh, S. Moitra, J.Kundu, A.K. Mukhapadhyaya, and S.k. Parui, "Design of a dual polarized rectangular patch antenna using DGS," Pro. of IEEE Applied Electromagnetics Conference (AEMC), 2011. doi: 10.1109/AEMC.2011.6256813.

21. Yadav, V.K. Singh, and H. Mohan, "Design of a U-shaped circularly polarized wearable antenna with DGS on a fabric substrate for WLAN and C-band applications," Journal of Computational Electronics, vol.18, pp. 1103-1109, 2019. doi: 10.1007/s10825-019-01342-2.

22. S. Pandit, P. Ray, and A. Mohan, "Compact MIMO antenna enabled by DGS for WLAN applications," Pro. of IEEE International Symposium on Antennas and Propagation \& USNC/ URSI National Radio Science Meeting, 2018.doi: 10.1109/ Apusncursinrsm.2018.8609389.

23. Elfergani, A.S.Hussaini, A.M. Abdalla, J. Rodriguez and R.Abd-Alhameed, "Millimeter Wave Antenna Design for 5G Applications," Optical and Wireless Convergence for 5G Networks, edition.1, pp. 139-56, 2019.

24. Sanyog Rawat and K. K. Sharma, "A compact broadband microstrip patch antenna with defected ground structure for C-Band applications," Cent. Eur. J. Eng, vol.4, no. 3, pp. 287-292, 2014.

25. Rashmi A. Pandhare, Prasanna L. Zade and Mahesh P. Abegaonkar, "Miniaturized microstrip antenna array using defected ground structure with enhanced performance," International Journal of Engineering Science and Technology, vol.19, pp.1360-1367, 2016.

26. V.N. Lakshmana Kumar, M. Satyanarayana and S.P. Singh, "A Nove Technique for Sidelobe and Backlobe Reduction in Rectangular Microstrip Antenna Array Using Defected Ground Structures," International Journal of Applied Engineering Research, vol.13, no. 22, pp. 15961-15966, 2018.

27. Bondili S. Hari Prasad and Mokkapat V. S. Prasad, "Design and Analysis of Compact Periodic Slot Multiband Antenna with Defected Ground Structure for Wireless Applications," Progress in Electromagnetics Research M, vol. 93, pp. 77-87, 2020.

28. M.A. Matin, "Review on millimeter wave antennas-potential candidate for $5 \mathrm{G}$ enabled applications," Advanced Electromagnetics, vol.5, pp.98-105, 2016.

\section{AUTHORS PROFILE}

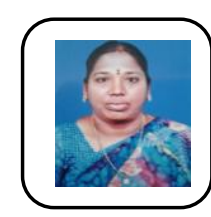

Suganthi Santhanam, completed her Ph.D in RF MEMS, having more than 22 years of teaching experience and presently working as Professor in ECE department. Her areas of interest are Microwave devices modeling \& simulation, DSP \& Image Processing, Neural Network simulation.

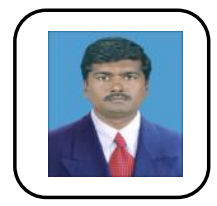

Thiruvalar Selvan Palavesam, completed his Ph.D in Microwave transmission line modeling in NIT, Trichy, having more than 25 years of teaching experience and presently working as Professor in ECE department. His areas of interest are Microwave devices modeling \& simulation.

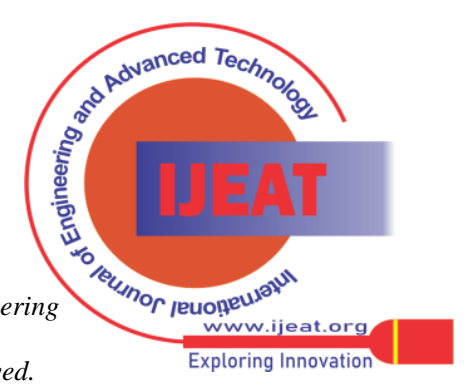

